\title{
Mídia e globalização neoliberal
}

Dênis de Moraes*

\section{RESUMO}

Este artigo analisa o duplo papel estratégico das corporações de midia na contemporaneidade: esfera que legitima o discurso da globalização neoliberal e importante agente economico global. Pretende-se demonstrar como os grupos de midia se estruturam em redes corporativas para dominar os negócios de informação e entretenimento em todo o planeta, reduzindo a competição a um pequeno número de players. À luz deste cenário, o estudo também avalia problemas e desafios para democratizar os sistemas de comunicação.

\section{ABSTRACT}

This article analyses the double role of the media corporations in the contemporary: sphere that legitimates the globalization's discourse and important global economics agent. The propose is to give evidence of the media groups' organization in corporative networks to dominate the information and entertainment business in all the planet, decreasing the competition in a few number of players. Based in this scenery, the paper also evaluates problems and defiances to obtain democratic communication systems.

\footnotetext{
*Este trabalho é dedicado a René Armand Dreifuss. Dênis de Moraes é doutor em Comunicação e Cultura pela UFRJ e pós-doutor em Letras pela UFMG. É professor do Mestrado em Comunicação, Imagem e Informação da UFF e pesquisador do CNPq. Publicou, entre outros livros, Clobalização, midia e cultura contemporânea, org. (1997), O Planeta Midia: tendências da comunicação na era global (1998) e O concreto e o virtual: midia, cultura e tecnologia (2001).
} 


\section{O duplo papel da mídia global}

"Somos a blue chip do novo milênio". A metáfora, cunhada por Gerald Levin, diretor-executivo da AOL-Time Warner, define bem o lugar privilegiado que as corporações de mídia ocupam na contemporaneidade. ${ }^{1}$ Com efeito, os conglomerados de informação e entretenimento exercem um duplo papel estratégico. O primeiro diz respeito à sua condição peculiar de agentes operacionais da globalização, do ponto de vista da enunciação discursiva. Não apenas vendem e legitimam o ideário global, como também o transformam no discurso social hegemônico, propagando visões de mundo e modos de vida que transferem para o mercado a regulação das demandas coletivas. A retórica da globalização intenta incutir a conviç̧ão de que a fonte primeira de expressão cultural se mede pelo nível de consumo dos indivíduos e coletividades. Como se somente o mercado pudesse aglutinar o que se convencionou chamar de organização societária.

Cabe à mídia azeitar a base de sustentação ideológica para a reprodução ampliada do capitalismo. Os aparatos de veiculação constroem socialmente um ambiente de expectativas propícias, fazendo setores influentes da opinião pública acreditarem que não há alternativa sócio-econômica fora dos pressupostos neoliberais. Trata-se de "fabricar o consenso" sobre a hipotética superioridade das economias abertas e globalizadas. ${ }^{2} \mathrm{O}$ "pensamento único" - feliz expressão de Ignacio Ramonet para designar a matriz ideológica que subordina os direitos sociais dos cidadãos à razão competitiva dos mercados financeiros ${ }^{3}$ - oculta, intencionalmente, a carga atômica de desigualdades e exclusões.

Ao mesmo tempo em que reverberam o que Pierre Bourdieu define como "a doxa invasiva e insinuante do neoliberalismo"4, os conglomerados de mídia atuam como agentes econômicos globais. Segundo o banco de investimentos Veronis Suhler, as indústrias de informação e diversão foram o setor de crescimento mais rápido da economia norte-americana entre 1994 e 2000 — à frente dos mercados financeiro e de serviços. ${ }^{5}$ Mesmo que o desempenho possa ser afetado pela retração das verbas publicitárias e pela desaceleração internacional, a consultoria UBS Warburg prevê que os investimentos em comunicação continuarão a crescer a médio e a longo prazos. ${ }^{6}$

A grande mídia assim opera tanto por adesão ideológica à globalização, quanto por deter a capacidade única de interconectar o 
planeta, através de satélites, cabos de fibra óptica e redes infoeletrônicas. Não creio existir outra esfera da vida cotidiana habilitada a interligar, em tempo real e on line, povos, países, sociedades, culturas e economias. A característica integradora é algo intrínseco aos complexos de difusão. Eles concatenam. simbolicamente, as partes das totalidades, procurando unificá-las em torno de determinadas significações.

Numa época em que os dispositivos tecnológicos tornam próximos $\mathrm{c}$ presentes acontecimentos separados por fusos horários. climas e injunções geopolíticas, as longas durações e os extensos territórios ficam obsoletos. Eles pertenciam, segundo Zygmunt Bauman. à era do hardware, ou "modernidade pesada". em que tamanho, volume, peso, parques industriais e conquistas teritoriais constituíam medidas de poder. O mundo de agora valoriza a instantaneidade do software. que delineia uma "modernidade líquida", em que prevalecem a leveza. a flexibilidade e o mínimo de estruturats, indispensáveis à volatilidade das transações financeiras eletrônicas. Os softwares suplantam a lógica dos lugares e esboçam uma existência à velocidade da luz. Assim. pontua Bauman, "o espaço pode ser atravessado, literalmente. em 'tempo nenhum"; cancela-se a diferença entre 'longe' a 'aqui". pois o espaço não impõe mais limites à ação e seus efeitos, e conta pouco. ou nem conta"?

O capital precisa de total fluidez para estar em constante deslocamento, deslizando pelos continentes atrás de escala e rentabilidade, sem as amarras dos ativos pesados e dispendiosos de outrora. Nesse sentido, a fluidez não representa um bem comum, não é para todos. Apenas grandes empresas e instituições hegemônicas têm a possibilidade de utilizá-la, tornando-se "os detentores efetivos da velocidade"."

Este é o significado concreto da articulação existente entre o modo de produção capitalista e as tecnologias de comunicação e informação: uma sinergia que alimenta a acumulação de capital financeiro numa economia de interconexões eletrônicas." Nunca é demais sublinhar a posição distintiva do sistema tecnológico: ele incorpora ao capitalismo a sua lógica, caracterizada, na visĩo de Manuel Castells, "pela capacidade de traduzir todos os aportes de informação em um sistema comum e de processá-los a velocidades crescentes. 
com uma potência em progresso, a um custo decrescente, através de uma rede de distribuição virtualmente ubíqua."10

Os grupos de mídia buscam alcançar os parâmetros de lucratividade que norteiam as ações dos gigantes transnacionais. Não vejo distinção relevante entre filosofias, metas, estruturas operativas e focos mercadológicos. No decorrer da década de 1990, as indústrias de comunicação adequaram-se às linhas-mestras da corporação-rede. Segue-se um figurino multissetorial e integrado, isto é, exploram-se, simultaneamente, ramos conexos, promovendo sinergias capazes de racionalizar custos, conjugar know how e economizar na escala. A partir de um planejamento mundializado, confere-se maior liberdade operacional às unidades regionais, preservando, contudo, os vínculos de dependência às diretivas da holding.

AOL-Time Warner, News Corp., Viacom: nada difere os seus contornos corporativos dos de mastodontes como a General Motors, a McDonald's e a IBM. As diferenças localizam-se nas áreas específicas de atuação - muito embora essa separação venha se reduzindo a olhos vistos, em função da convergência multimídia, dos investimentos plurissetoriais, de alianças, fusões e participações cruzadas.

Em síntese, as corporações de mídia projetam-se, a um só tempo, como agentes discursivos, com uma proposta de coesão ideológica em torno da ordem global, e como agentes econômicos presentes nos hemisférios. Evidenciar esse duplo papel me parece fundamental para entendermos a sua forte incidência na atualidade.

\section{Lógica das redes e poder planetário}

Gostaria de mencionar três pontos que ajudam a fixar o perfil da mídia global. Primeiro: vivemos uma mudança de paradigma comunicacional. Do gabarito mediático evoluímos para o multimediático ou multimídia, sob o signo da digitalização. A linguagem digital única favorece a interconexão de redes e plataformas, viabilizando a base material para a hibridação das infra-estruturas de transmissão de dados, imagens e sons, em proporções incalculáveis.

Em razão dessa confluência, dissipam-se as fronteiras tradicionais entre operadoras de TV a cabo, de telecomunicações, de radiodifusão e de informática. Os novos canais e suportes (Internet, DVD, TV interativa de alta definição, celulares com Web móvel e os tantos que virão) multiplicam a geração de conteúdos informativos, 
financeiros, culturais e comerciais.

A soma dos prefixos dos setores convergentes (informática, telecomunicação e comunicação) em uma só palavra infotelecomunicações - designa a conjunção de poderes estratégicos relacionados ao macrocampo multimídia. O paradigma infotelecomunicacional constitui vetor decisivo para a expansão dos complexos mediático, tendo por escopo a comercialização diversificada e sem limites geográficos.

Não espanta, por exemplo, que a Disney migre para a telefonia celular em parceria com a operadora japonesa NTT DoCoMo. Uma aliança sedutora para os dois lados: a NTT disponibiliza produtos da Disney a seus usuários de Web móvel, enquanto os assinantes do colosso norte-americano acessam vídeos e clipes musicais através de celulares de terceira geração. O ponto nodal é agregar valor ao leque multimídia, com o menor custo possível.

Os conglomerados tratam de otimizar as cadeias produtivas para lucrar em todas as pontas. "Se pensarmos na música digital, na televisão interativa, nos serviços de banda larga e nas redes domiciliares, veremos que estamos no centro de tudo isso", acentua Gerald Levin. da AOL-Time Warner." Ambição semelhante tem a Disney, conforme o seu presidente para a América Latina, Diego Lerner: "Em nosso plano estratégico, existe a expansão de meios na forma mais direta. Fizemos uma revolução nos últimos dois anos e isso mudou nossa imagem. Antes éramos uma companhia de brinquedos; agora somos vistos como uma companhia global com forte presença nos grandes mercados. Ou seja, uma companhia que oferece produtos a todo público. Programas na TV aberta, conteúdos gráficos, Internet, eventos e iniciativas destinadas a todas as linhas de produtos." 12

Liderar a indústria multimídia também é o alvo da Vivendi Universal, segundo maior conglomerado mundial de informação e entretenimento, de acordo com o big boss Jean-Marie Messier: "É essencial agregar conteúdos baseados em alta tecnologia, sobretudo os da Internet, aos nossos serviços e produtos. A combinação de conteúdos, de meios de difusão e de produtos afins nos dá uma vantagem considerável perante nossos concorrentes. Podemos ampliar as ofertas aos clientes, com redução de custos. Essa estratégia integrada é a que se adapta melhor à revolução das redes, incrementando as vendas." 13

O segundo ponto a realçar refere-se ao modelo organizacional das corporações de mídia. Durante o reinado neoliberal, ocorre um processo 
brutal de desregulamentação, de privatização, de depreciação do papel do Estado como âmbito de representação pública e de esvaziamento proposital da sociedade civil e dos laços comunitários. A abertura desenfreada coloca por terra as salvaguardas nacionais porventura existentes. Os megagrupos - a maioria dos quais sediada nos Estados Unidos da América - passam a usufruir de um amplo campo de manobras, desvencilhando-se de normas, regulamentos e leis. ${ }^{14}$

O padrão tecnoprodutivo apóia-se no mandamento de que as corporações devem gerir seus empreendimentos a partir de um centro estratégico - a holding -, incumbido de pensar e formular prioridades, diretrizes e planos de inovação, além estabelecer parâmetros de rentabilidade para subsidiárias e filiais. A holding é o pólo de inteligência e decisão ao qual se remetem as estratégias locais, nacionais e regionais. Ela organiza a instituição de cima a baixo, em fragmentos e nódulos de uma rede formada por eixos estratégicos comuns.

A gestão corporativa flexibiliza-se com a descentralização das unidades e a crescente autonomia dada a cada uma delas, permitindo até que concorram entre si, a partir de uma estratégia global comum..$^{15}$ É o caso da AOL e da Bertelsmann, que firmaram parceria nas operações de Internet na Europa, até 2004. As arqui-rivais Disney e

12 News criaram a Movies.com para oferecer filmes e programas no sistema de TV a cabo digital.

O êxito da corporação-rede vincula-se, em considerável medida, ao aprimoramento contínuo das tecnologias de informação. Elas possibilitam às holdings comandar à distância a malha de filiais e subsidiárias. Daí porque os dispositivos informacionais terem se tornado insubstituíveis para ajustar as empresas às condições mutáveis dos mercados globalizados, tanto no que se refere à demanda de dados atualizados quanto à absorção de novas tecnologias. ${ }^{16} \mathrm{~A}$ informação é pedra-de-toque na constituição de dividendos competitivos, notadamente através de intercâmbio de dados que maximizam a eficiência das cadeias produtivas, induzindo a sinergias baseadas no conhecimento $\mathrm{e}$ na capacidade de resposta.

Não será por outro motivo que os investimentos em tecnologias de informação vêm crescendo desde a segunda metade da década de 1980. A International Data Corporation prevê para o biênio 2002-2003 um aumento de gastos no setor entre 4\% e 6\% nos Estados Unidos, 7\% na Europa Ocidental e entre 10\% e 12\% na Ásia.17 
As organizações interconectam investimentos dispersos geograficamente, sob a égide de uma racionalidade empresarial única. As holdings levam em conta certas particularidades socioculturais das regiões em que operam. Os dados provenientes de um determinado tempo-espaço constituem componentes preciosos para uma adaptação consistente e para planos inovadores. Implica preterir planejamentos verticalizados, que se limitam a exportar concepções produtivas e eixos mercadológicos, desconhecendo peculiaridades regionais. O desafio é combinar traços específicos com as metas gerais de comercialização, generalizando a impressão de que os produtos não conhecem fronteiras e pairam acima de singularidades geoculturais.

As redes globais contribuem para diminuir as matrizes de produção e alargar as zonas de consumo, com enormes ganhos de produtividade. O presidente da Sony, Nobuyuki Idei, confirma: "Nós perseguimos um modelo de administração que seja ao mesmo tempo integrada e descentralizada. A empresa fornece as estratégias mais abrangentes, mas as divisões têm considerável autonomia. Como a Sony reúne diversas culturas de negócios, como equipamento eletrônicos, entretenimento e jogos, tentamos permitir que essas culturas se desenvolvam livremente e, ao mesmo tempo, queremos conectá-las de forma criativa e lucrativa." 18

Temos, portanto, uma concentração de poder sem centralização operacional. Todavia, não percamos de vista que a essa flexibilidade é relativa, pois as filiais permanecem no raio de eventuais reorientações da matriz. A holding mantém ascendência sobre o todo, mas desfaz as estruturas piramidais de comando.

\section{Competição restrita a gigantes}

AOL-Time Warner, Vivendi Universal, Disney, News, Bertelsmann e Viacom, as seis primeiras do ranking de mídia e entretenimento, têm idênticas pretensões de domínio: estar em toda parte, a qualquer tempo, para exercer hegemonia. A competição restringe-se a um número mínimo de corporações que dispõem de poderio financeiro, know how, parques industriais e redes de comercialização para interligar bases de consumo pelos hemisférios.

O resultado é uma concentração da mídia nas mãos de cerca de duas dezenas de conglomerados, com receitas entre US\$ 5 bilhões e US $\$ 30$ bilhões. Eles veiculam dois terços das informações e dos 
conteúdos culturais disponíveis no planeta. Esse grau de hiperconcentração, de resto, reproduz o que acontece no comércio internacional, em que dois terços das transações estão nas mãos de mastodontes globais. De um total de 40 mil empresas transnacionais, as 100 maiores $(0,3 \%)$ detêm um terço do estoque mundial de capital, sendo que 32 são norte-americanas e 19 japonesas. ${ }^{19}$

Na dinâmica tecnoprodutiva, ocupam lugares de destaque as fusões, parcerias e joint ventures. Ao optarem por estratégias de colaboração, as megafirmas visam aumentar seus lucros, seja reduzindo e repartindo despesas e perdas, seja contornando fatores de risco principalmente os decorrentes da instabilidade econômica e do encolhimento da vida útil das mercadorias.

Os projetos exigem aportes financeiros e logística adequada, a fim de facilitar o escoamento nas praças internacionais. Alianças apressam o ingresso em regiões com potencial de consumo, valendose dos canais de distribuição e das vivências dos sócios locais. O acréscimo de competências vem no bojo da complementaridade de especializações e recursos.

Ao efetuar promoções cruzadas entre suas 200 empresas, a AOL-Time Warner deverá economizar US\$1 bilhão entre 2002 e 2003, conforme avaliação do banco de investimentos Morgan Stanley. ${ }^{20}$ Veja o alcance do acordo entre Vivendi Universal e a operadora de TV via satélite EchoStar. Durante oito anos, a EchoStar utilizará o sistema MediaHighway - desenvolvida pela subsidiária da Vivendi, Canal Plus Technologies - como plataforma para gravações de vídeos caseiros e serviços de TV interativa, além de download e acesso instantâneo a filmes e músicas. A Vivendi e a EchoStar planejam criar novos canais de banda larga via satélite com jogos interativos, filmes, programas de esportes, educação e música on line. ${ }^{21}$

$\mathrm{Na}$ mão oposta, estreita-se a margem de participação de empresas de menor porte nos negócios de ponta. As pequenas e médias firmas passam a explorar nichos mercadológicos ou se tornam fornecedoras de produtos e serviços especializados ou terceirizados. Em ambos os casos, orbitam em torno da economia de escala das corporações e precisam demonstrar produtividade, agilidade e criatividade para sobreviver.

Ainda flagramos a emergência de outro fenômeno perturbador: as gigantes estão engolindo grandes empresas. A Viacom fisgou a 
CBS, uma das quatro maiores redes mundiais de TV, e hoje controla $40 \%$ das emissoras de TV norte-americanas. A Interpublic, número 1 da publicidade global, incorporou em 2000 a True North, até então a oitava no ranking. A sua rede de agências, que inclui McCann-Erickson, Lowe Lintas e FCB, atende a cinco mil clientes. A francesa Publicis tornou-se a quarto maior holding de publicidade ao adquirir, em março de 2002, a norte-americana Bcom3, atć então a nona do ranking. A Publicis, que havia incorporado a britânica Saatchi \& Saatchi, terá uma receita de 49\% nos EUA, 37\% na Europa, 9\% na Ásia-Pacífico e 5\% no restante do mundo. Conseguirá uma porta de entrada no lucrativo mercado japonês, já que a Dentsu, maior grupo publicitário asiático, detém $21 \%$ da Bcom3. A carteira da Publicis engordará com os anunciantes pesos-pesados da Bcom3, como General Motors, Delta Air Lines, Procter \& Gamble, Walt Disney, Heineken c AT\&T.22

A Vivendi absorveu, de uma só vez, a Universal Studios e a Universal Music, ambas situadas entre as maiorais de seus respectivos ramos. E continuou investindo nos EUA: em 2001, comprou a USA Networks (produtora de programas de TV e operadora dos canais a cabo USA Network e Sci-Fi) e o site MP3.com, e ainda aplicou US\$ 1,5 bilhão na EchoStar. Graças à coordenação das atividades de suas empresas de cinema e TV (Universal, Studio Canal, Canal Satellite c Telepiù), a Vivendi registrou crescimento de $8 \%$ naqueles setores em 2001.23

Como efeito extremamente maléfico da confluência de recursos operacionais e criativos, sucedem-se ondas de demissões e cortes de gastos. A Interpublic demitiu 5.700 funcionários e fechou 70 escritórios em 2001. A Disney dispensou 4 mil empregados e a AOL-Time Warner. 3 mil. ${ }^{24}$ Robert Kurz sublinha que, para o conjunto do capital social. fusões e incorporações provocam um efeito destrutivo, visto que. no cômputo geral, empregos e capital são mais aniquilados do que recriados. "Uma grande parte das incorporações, abstraindo o outsourcing, só serve para tirar proveito da disparidade de custos, ou seja, para fechar setores relativamente dispendiosos da empresa e reabri-los em outras localidades, com encargos tributários e impostos ecológicos menores e salários mais baixos. (...) Mesmo quando as empresas incorporadas continuam a produzir, a fusão é acompanhada, em geral, do surto de racionalização na esfera administrativa: empregos são extintos, setores inteiros da hierarquia são eliminados e filiais fecham suas portas." 25 


\section{Dilemas e perspectivas na arena transnacional}

Volto a afirmar que tal moldura oligopolística se consolida no vácuo aberto pela inexistência de marcos regulatórios e pela deliberada omissão dos poderes públicos e de organismos multilaterais. As disparidades tecnológicas e os frágeis mecanismos de regulação dos fluxos internacionais beneficiam as corporações, sobretudo as norteamericanas. $^{26}$

O caso da indústria cinematográfica dos EUA é eloqüente. Metade de suas receitas provém do exterior, o que representa salto expressivo, pois, em 1980, as praças internacionais contribuíam com $30 \%$. Em 2000, o público de cinema no Brasil foi de 68 milhões de espectadores, sendo que quase $80 \%$ pagaram ingressos para assistir a filmes norte-americanos, cabendo à produção nacional irrisórios 10,3\% das bilheterias. ${ }^{27}$ As principais cadeias de distribuição e exibição em nosso país pertencem a um cartel formado por grupos norte-americanos - como de resto acontece em $3 / 4$ dos mercados cinematográficos do planeta. Os filmes norte-americanos absorvem $70 \%$ das bilheterias dos cinemas da França, restando apenas $27 \%$ para as películas nacionais e $3 \%$ para as dos demais países. Há uma década, segundo o Centro Nacional de Cinema daquele país, os filmes franceses e norte16 americanos tinham o mesmo número de espectadores.

Os globalófilos poderiam argumentar que nunca a humanidade se deparou com tantas informações e imagens, tantos acessos à cultura e ao entretenimento. Caberia objetar: mas quem comanda e centraliza a disseminação dos bens simbólicos? quem agencia os acessos? quem define o que vai ser fabricado e como e onde divulgado?

Estamos diante de um impasse: cresce intensamente a oferta as mercadorias e serviços, tanto aqueles para públicos massificados quanto os direcionados a segmentos de consumidores, mas não pára de se concentrar a propriedade dos meios de produção e distribuição. Estruturadas em redes intra/inter/multissetoriais, as corporações transnacionais estendem seus tentáculos por ramos correlatos, interligam unidades descentralizadas e sincronizam programas de investimentos e processos decisórios.

Antonio Negri e Michael Hardt resumem, numa imagem sem retoques, essa feição oligopolística das engrenagens de difusão: "uma estrutura em forma de árvore, que subordina todos os galhos à raiz central". Isto porque, argumentam, "existe um ponto único e relativamente fixo de emissão, mas os pontos de recepção são 
potencialmente infinitos e territorialmente indefinidos"”.,.28 Onde quer que se pretenda atuar em mídia, lá estará fincada a bandeira de um player global.

Considero alarmante o fato de convivermos com uma abundância de dados, sons e imagens que se originam, via de regra, de fontes de enunciação e emissão controladas por um número mínimo de superempresas - as mesmas que se movimentam livremente pela Terra, sem prestar contas a ninguém, exceto a seus acionistas. A industrialização dos bens simbólicos obedece, assim, às injunções mercadológicas e às conveniências políticas e econômicas dos titãs.

Segundo Jeremy Rifkin, não existem precedentes de um tipo de controle tão amplo das comunicações: "Os gigantescos agrupamentos de companhias de mídia e provedores de conteúdos se convertem em 'vigilantes' que determinam as condições e os termos pelos quais um bilhão de pessoas podem se comunicar entre si. É uma nova forma de monopólio comercial global, exercido sobre as experiências vitais de uma ampla porcentagem da população mundial."29

Se desejamos o livre fluxo de informações, é hora de revitalizar a sociedade civil e arregimentar forças comunitárias para a ingente tarefa de propor alternativas concretas à mercantilização generalizada. Insistamos, por exemplo, no estabelecimento de políticas públicas de comunicação, assentadas em mecanismos democraticamente instituídos de regulação, de concessão, de tributação e de fiscalização. Políticas debatidas por segmentos representativos da opinião pública e formuladas com equilíbrio e realismo. Políticas que não desconheçam as profundas transformações da era digital e seus efeitos socioculturais e políticos.

Os obstáculos se sucederão, porque a organização da cidadania é lenta, sujeita a dilemas, tensões, avanços e recuos, ainda mais com a necessidade de concatenação em âmbito global. Não percamos de vista que, no curso da integração transnacional, a reivindicação de prevalência pública sobre os interesses corporativos não pode limitarse a contrafortes dentro de cada nação; tem que almejar formas supranacionais de resistência e mobilização. Os poderes efetivos são globalizados, enquanto os instrumentos sociais de controle, influência e pressão apenas esboçam transcender aos níveis locais e regionais. ${ }^{30}$

Michael Löwy foi exato ao sustentar que "cada vez aparece mais a necessidade urgente de unir forças, intercambiar experiências, 
articular iniciativas, de modo a constituir um pólo alternativo, um contrapoder, uma Internacional da Resistência à globalização capitalista". ${ }^{31}$

No bojo da retomada da discussão política, começam a surtir efeito esforços para uma junção de forças contra-hegemônicas. Basta ver a escalada de protestos antiglobalização (Seattle, Nice, Praga, Quebec, Barcelona, Gotemburgo, Washington, Davos e Gênova) e a sucessão de encontros internacionais que ampliam os espaços de reivindicações pelos direitos da cidadania.

A questão-chave é propor e consolidar novos modelos de democracia participativa, de desenvolvimento econômico comunitário e democratização dos meios e tecnologias de comunicação — modelos que revertam os efeitos perversos da globalização. Os Fóruns Sociais Mundiais, realizados em Porto Alegre, provaram ser possível estabelecer nexos, interdependências e laços de solidariedade entre organismos não-governamentais e movimentos antineoliberais de vários continentes. Em 2002, o II FSM reuniu 51.300 participantes de 210 etnias e 186 línguas, sendo 15.230 delegados de 4.909 entidades de 131 países.

Atilio Borón qualifica encontros dessa natureza como "embriões de um novo internacionalismo, mais necessário do que nunca em face dos estragos provocados pela globalização do capital, à qual só se pode opor resistência efetiva com a mundialização de lutas sociais (...) que demonstrem capacidade de articular o local com o global, o micro com o macro". 32

Uma coligação cívica supranacional enfrentará percalços de toda ordem, a começar pelo mosaico de interesses e prioridades dos atores participantes, perceptível em seus horizontes estratégicos (curto, médio e longo prazos), metodologias de atuação (movimentos autônomos ou redes) e raios de abrangência (internacional, nacional, regional ou local). Do mesmo modo, será grave erro subestimar o poder de fogo das megacorporações e dos arautos da governança global (Fundo Monetário Internacional, G-8, Banco Mundial). Eles resistirão tenazmente a qualquer perda de mando. Mas há que se perseverar para viabilizar uma "agenda comum de iniciativas e mobilizações que respeite a diversidade e a pluralidade dos movimentos que se opõem à globalização neoliberal". ${ }^{33}$

Parece-me decisivo multiplicar as frentes de ação compartilhada e, sobretudo, as redes de entidades, associações e coletivos, dentro e fora da Internet. Com baixo custo econômico e rapidez, as redes têm 
autonomia para difundir extensivamente informações e conhecimentos, sem controles externos. Ao mesmo tempo, promovem o diálogo e a cooperação à distância, facilitando a convergência de iniciativas e campanhas, e reforçando a sociabilidade política baseada em visões de mundo afins. Os nós interativos podem servir de estuários para a defesa de identidades culturais e do pluralismo, para a promoção de valores éticos e para a longa luta pela democratização da esfera pública. A teia de conexões permite aperfeiçoar táticas de denúncia, resistência, pressão e insurgência contra o statu quıo.

A despeito das dificuldades, penso ser essencial uma coordenação permanente entre entidades, fóruns e redes empenhados em fortalecer direitos sociais e viabilizar sistemas de comunicação pluralistas e descentralizados (como almeja a Organização das Nações Unidas com as Conferências Mundiais para a Sociedade da Informação de 2003, em Genebra, e de 2005, em Túnis) $)^{34}$. Torna-se, pois, crucial conceber alianças e coalizões de forças de todos os quadrantes, como meio de tentar frear, em um duradouro processo de lutas, a neurose do lucro a qualquer preço, que também se alastra pelo campo da comunicação.

\section{Notas:}

${ }^{1}$ Gerald Levin, citado por Carol Matlack, "É a nova ordem da velha economia", Valor Econômico, 4 de julho de 2001.

${ }^{2}$ Segundo Atilio Borón, o êxito do neoliberalismo no terreno ideológico-cultural pode ser medido pelas mudanças no sentido de algumas palavras, a partir da difusão da catilinária neoliberal. Ele exemplifica: "O vocábulo 'reforma', por exemplo, que antes tinha uma conotação positiva e progressista - e que, fiel a uma concepção iluminista, remetia a taansformações sociais e econômicas orientadas na direção de uma sociedade mais igualitária, democrática e hunnana — foi apropriado e 'reconvertido' pelos ideólogos do neoliberalismo em um significante que alude a processos e transformações sociais com claro sentido involutivo e antidemocrático. As 'reformas econômicas' postas em prática em anos recentes na América Latina são, em realidade, contra-reformas orientadas para aumentar a desigualdade econômica e social e esvaziar de todo conteúdo as instituições democráticas." Ver Atilio Borón, "Sobre mercados y utopías: la victoria ideológico-cultural del neoliberalismo", La Insignia, 9 de março de 2002, disponivel em http://www.lainsignia.org/2002/marzo/econ_010.htm. 
3 Ignacio Ramonet, "Régimes globalitaires", Le Monde Diplomatique, janeiro de 1997.

${ }^{4}$ Pierre Bourdieu. Contre-feux 2. Paris: Raisons D'Agir, 2001, p. 89.

${ }^{5}$ Cibele Santos, "Projeções para a indústria de comunicações dos EUA",

Meio e Mensagem, dezembro de 2000.

${ }^{6}$ The Economist, 30 de outubro de 2001.

7 Zygmunt Bauman. Modernidade líquida. Rio de Janeiro: Jorge Zahar, 2001, p. 132-142.

${ }^{8}$ Ver Milton Santos. Por uma outra globalização: do pensamento único à consciência universal. Rio de Janeiro: Record, 2000, p. 83-84.

${ }^{9}$ Manuel Castells. La sociedad red (La era de la información: economía, sociedad y cultura, vol. 1). Madri: Alianza Editorial, 1998, p. 506-510.

${ }^{10}$ Ibidem, p. 59.

${ }^{11}$ Gerald Levin, já citado por Carol Matlack.

${ }^{12}$ Diego Lerner, citado por Diego Fonseca, "Disney busca a magia perdida", América Economia, 18 de agosto de 2001.

${ }_{13}$ Jean-Marie Messier. Communication: la stratégie de Vivendi

20 Universal. Discurso pronunciado na assembléia anual dos acionistas da Vivendi Universal, em Cannes, 11 fevereiro de 2001, disponível em http://www.vivendi.fr.

${ }^{14}$ Sobre os impactos das desregulamentações neoliberais no setor de mídia, consultar Dênis de Moraes. O Planeta Múdia: tendências da comunicação na era global. Campo Grande: Letra Livre, 1998, p. 63-66.

${ }^{15}$ Ver Manuel Castells, La sociedad red, ob. cit., p. 192-193.

${ }^{16}$ Consultar François Chesnais. A mundialização do capital. São Paulo: Xamã, 1998, p. 103.

17 The Wall Street Journal, 3 de janeiro de 2002.

${ }^{18}$ Nobuyuki Idei, citado por Carlos Rydle. "O pai da invenção", Veja, 23 de maio de 2001.

19 Ver José Luiz Fiori. 60 lições dos 90: uma década de neoliberalismo. Rio de Janeiro: Record, 2001, p. 26.

${ }^{20}$ Financial Times, 26 de setembro de 2001

${ }^{21}$ George A. Chidi Jr. "Vivendi investe US\$ 1,5 bi na EchoStar para TV interativa", IDG News Service, 14 de dezembro de 2001.

${ }^{22}$ Carlos Coelho e Cibele Santos. "Publicis compra a Bcom3 por US\$ 
3 bilhões", Meio e Mensagem, 3 de março de 2002.

${ }^{23}$ Relatório da Vivendi Universal sobre o exercício de 2001, divulgado em janeiro de 2002 e disponível em http://www.vivendi.fr.

${ }^{24}$ The Wall Street Joumal, 27 de julho de 2001.

${ }^{25}$ Robert Kurz, "A orgia do capitalismo", Folha de S. Paulo (Mais!), 31 de maio de 1998.

${ }^{26}$ A oligopolização da mídia deverá acentuar-se ainda mais nos Estados Unidos, se não for revista a decisão da Corte de Apelações do Distrito de Columbia, em fevereiro de 2002, que suspendeu as regras de propriedade cruzada da Federal Communications Commission. A FCC proibia qualquer empresa ou instituição de controlar sistemas de TV a cabo e estações de TV aberta num mesmo mercado, ou de possuir estações abertas com penetração superior a $35 \%$ em domicílios nacionais servidos por televisão. ${ }^{27}$ Cláudio Renato, "Novos planos para o cinema brasileiro", Gazeta Mercantil, 7 de maio de 2001.

${ }^{28}$ Antonio Negri e Michael Hardt. Império. Rio de Janeiro: Record, 2001, p. 320-321.

${ }^{29}$ Jeremy Rifkin. La era del acceso: la revolución de la meva economía. Barcelona: Paidós, 2000, p. 22.

${ }^{30}$ Ver Zygmunt Bauman. Em busca da política. Rio de Janeiro: Jorge Zahar, 2000, p. 172.

${ }^{31}$ Michael Löwy. A luta contra o capital global não tem fronteiras. Conferência pronunciada no Fórum Social Mundial, Porto Alegre, janeiro de 2001.

${ }^{32}$ Atilio Borón, "Reflexiones a propósito del Foro Social Mundial, 2002", Rebelión, 10 de março de 2002, disponível em http://www.rebelion.org/ sociales/boron090302.htm.

${ }^{33}$ Idem, ibidem.

${ }^{33}$ As Conferências Mundiais para a Sociedade da Informação terão o propósito de definir estratégias e responsabilidades dos setores envolvidos, incluindo os Estados nacionais, e garantir conquistas da sociedade civil relativas às infraestruturas de telecomunicações, ao direito de acesso econômico, social, cultural e científico, ao direito à comunicação, à educação mediada por tecnologias, à liberdade de expressão, à informação como bem público, ao direito à propriedade intelectual, além dodireito a pluralismocultural, diversidade, equidade, privacidade, sustentabilidade e transparência. 


\section{Bibliografia:}

BAUMAN, Zygmunt. A modernidade líquida. Rio de Janeiro: Jorge Zahar, 2001.

BAUMAN, Zygmunt. Em busca da política. Rio de Janeiro: Zahar, 2000.

BOURDIEU, Pierre. Contre-feux 2. Paris: Raisons D'Agir, 2001, p. 89. CASTELLS, Manuel. La sociedad red (La era de la información: economía, sociedad y cultura, vol. 1). Madri: Alianza Editorial, 1998. CHESNAIS, François. A mundialização do capital. São Paulo: Xamã, 1998. DREIFUSS, René Armand. A época das perplexidades: mundialização, globalização e planetarização - novos desafios. Petrópolis: Vozes, 1996.

FIORI, José Luís. 60 lições dos 90: uma década de neoliberalismo. Rio de Janeiro: Record, 2001.

JAMESON, Fredric. A cultura do dinheiro: ensaios sobre a globalização. Petrópolis: Vozes, 2001.

MCCHESNEY, Robert. Rich media, poor democracy: communication politics in dubious times. Nova York: New Press, 2000.

MIÈGE, Bernard. Les industries du contenu face à l'ordre informationnel. Grenoble: PUG, 2000.

22 na era global. Campo Grande: Letra Livre, 1998.

MORAES, Dênis de. $O$ concreto e o virtual: mídia, cultura $e$ tecnologia. Rio de Janeiro: DP\&A, 2001.

NEGRI, Antonio e HARDT, Michael. Império. Rio de Janeiro: Record, 2001.

PASSET, René. A ilusão neoliberal. Rio de Janeiro: Record, 2002.

RAMONET, Ignacio. A tirania da comunicação. Petrópolis: Vozes, 2000. RIFKIN, Jeremy. La era del acceso: la revolución de la nueva economía. Barcelona: Paidós, 2000.

SANTOS, Milton. Por uma outra globalização: do pensamento único à consciência universal. Rio de Janeiro: Record, 2000.

\section{Palavras-chave}

1. mídia

2. globalização

3. neoliberalismo

4. corporação-rede

5. democratização 